AVANT, Vol. XI, No. 2

ISSN: 2082-6710 avant.edu.pl/en

DOI: 10.26913/avant.2020.02.05

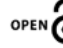

\title{
Affordances in Dennett's From Bacteria to Bach and Back
}

\author{
Zuzanna Rucińska \\ Centre for Philosophical Psychology, Department of Philosophy \\ University of Antwerp, Belgium \\ zuzannaaleksandra.rucinska@uanwerpen.be
}

Received 6 June 2019; accepted 2 July 2019; published 26 January 2020

\begin{abstract}
The purpose of this commentary is to elucidate the various roles that affordances play in Dennett's (2017) From Bacteria to Bach and Back. By looking at the multitude of ways that affordances are mentioned throughout the book, this commentary hopes to uncover the fruitful ways of talking about affordances in the philosophy of cognitive science.
\end{abstract}

Keywords: Daniel Dennett; From Bacteria to Bach and Back; affordances; cognitive science; explanation

\section{Introduction}

When interviewed by the online journal Edge (2017) and asked the question "What scientific term or concept ought to be more widely known?", Daniel Dennett responded: affordances.

For example, he writes:

(As) a revisionary description of the purpose of vision and the other senses, and a redirection of theorists' attention from retinal images to three-dimensional optical arrays (the information is in the light) through which the organism moves, Gibson's idea of affordances has much to recommend it - and we'll do a better job of figuring out how the neural machinery does its jobs when we better understand the jobs assigned to it.

Dennett seems to agree that the term 'affordance' is one of the most underappreciated terms in cognitive science today.

In From Bacteria to Bach and Back (2017), Daniel Dennett makes great use of the concept of affordance. Affordances feature as section titles such as 'Animals designed to deal with affordances' in Chapter 5 or 'How do brains pick up affordances?' in Chapter 8. There is a multitude of topics that the book covers, in which affordances feature (topics such as: language 
evolution, information processing, brain functioning or consciousness). There are also many ways the term 'affordance' has been conceptualised in the philosophical and psychological literature, as will be discussed below. This calls for paying special attention to how the notion of affordances is used throughout Dennett's book ${ }^{1}$. What does Dennett mean by affordances, and what roles (explanatory or descriptive) do they play in the developmental and evolutionary accounts that Dennett proposes? These and other questions will be addressed in the following commentary.

\section{Different characterisation of affordances}

Dennett provides us with a brief and straight-forward characterisation of affordances as introduced by Gibson. Affordances are "What the environment offers the animal for good or ill. Affordances are the relevant opportunities in the environment of any organism: things to eat or mate with, openings to walk through or look out of, holes to hide in, things to stand on, and so forth" (p. 79). This is a familiar, basic characterisation of affordances from ecological psychology, where affordances are possibilities for action that the environment offers to an animal.

Yet, things are not so simple, as the variety of conceptions of affordances in the literature show. There is an on-going debate in the affordance literature about how to conceive of affordances. The term 'affordance' has been used in multiple ways, by authors incl. Gibson (1979, 1982), Turvey (1992), Reed (1996), Chemero (2003, 2009), Noë (2004), Withagen et al. (2012), or Rietveld and Kiverstein (2014), to mention but a few. The concept of an affordance features in philosophy, ecological psychology, Gestalt psychology and phenomenology as well.

Are affordances to be found in the environment? Are they capacities of the organism to track the environment? Are they relational dispositions of the environment that are realised by organismic interaction with that environment? Are they simply relations? As I point out in other work, "the only consensus with respect to affordances is that they are possibilities for action. What they are (properties or relations), where they are located (in the environment or cutting across the environment-animal dichotomy), and how they work (whether they invite actions or not) is a matter of great debate" (Rucińska 2017, p. 259). Below I'll provide few examples from the existing literature on the disagreements in how to think of affordances. This serves to highlight just how rich is the concept of an affordance, before looking at Dennett's use of this term.

Reed (1996) claims that affordances are properties of the environment that are resources of that environment. He is taken to be a realist about affordances. As resources, affordances play the evolutionary role of selecting the animals and their skills. Here he follows Gibson's idea that things in the environment, and properties of the environment, offer or afford the animal

\footnotetext{
${ }^{1}$ From now on, references to and quotations from Dennett will imply references to and quotations from "From Bacteria to Bach and Back" (2017).
} 
opportunities to do things (find shelter, climb up, hide under, etc.). On this reading, the existence of affordances does not depend on the perceptually guided activity of the animal.

However, if we follow the embodied and enactive approach to cognition as described by Varela, Thomson and Rosch (1991), affordances should be understood in a more relational way, as dependent on how the animal perceives the world. The biological setup of the organism is crucial here; in an earlier work, Varela (1988) says that "living system brings forth its own world of relevance, and is not given in advance" and that "the meaning of this or that interaction is not given by an outside designer, but is the result of the organisation of the system itself and its history (ibid, p. 152)." Hence, the meaningfulness of the affordance does not come from the environment, but from the autopoietic interaction of the organism with its environment.

Turvey (1992) further claimed that "an affordance is an invariant combination of properties of substance and surface taken with reference to an animal" (p. 174). He considered affordances to be dispositional properties of the environment, which needed to be complemented, or paired with, relevant animal dispositions. The coupling allowed then to actualise affordances, or allow them to become manifest, and act as invitations for action.

Another substantially different school of affordances has emerged with Chemero (2003, 2009), who proposed a new ontology of affordances altogether, what he called 'affordances 2.0'. Chemero sees affordances not as properties, but as relations "between particular aspects of animals and particular aspects of situations" (2003, p. 190). Chemero proposes that affordances have the quality of being lovely (2009, p. 149), which means that affordances depend on there being a potential observer, not an actual act of observation.

Affordances do not disappear when there is no local animal to perceive and take advantage of them. They are perfectly real entities that can be objectively studied and are in no way figments of the imagination of the animal that perceives them. (...) But affordances do depend on the existence of some animal that could perceive them, if the right conditions were met (2009, p. 150).

Building on that view, Rietveld and Kiverstein (2014) argue that it is best to think of affordances as possibilities for action the environment offers to a whole form of life. On their view, affordances are relations not just between individual animals and their environments, but between the ecological niches and the whole animal species. That relation, for humans, extends to cultural environments.

There are other conceptions of affordances in the literature, varying from ideas such as affordances being 'of' the environment as forms of representations (Bickhard \& Ritchie, 1983), to affordances as Rylean, non-factual dispositions (Heras-Escribano, 2019), but this article cannot capture the entire spectrum of logical possibilities of the metaphysics of affordances. What it does try to do is provide a background to understanding which conception of affordances Dennett could have had in mind, and which conception he might have preferred that would be most in line with his philosophy. I will next explore the various ways the notion of affordance features in From Bacteria to Bach and Back (2017). 


\section{Which notion of affordance is used?}

It might seem that for the purposes of the book on the evolutionary history of minds, not on philosophical analysis of concepts, we need not engage in such detailed discussion on the nature of affordances. The gist should suffice. However, in From Bacteria to Bach and Back (2017) we see references to almost all of the variations of affordances mentioned above. Perhaps that is because all of these variations 'sound good' in some sense, and may have a distinct place in the evolutionary story. However, referring to all of them is problematic, as these conceptions are contradictory, so in principle, they should not all have a place in one conceptual story. Examples will now follow.

According to Dennett (2017), it may seem like affordances are to be found in the environment. He writes that affordances populate an Umwelt, or "the behavioral environment that consists of all the things that matter to its well-being" (p. 79). The affordances are characterised as relevant to the organism; they are "things that matter, in a broad sense of 'thing'" (p. 165). Yet they seem to be of the environment, as we see in the example Dennett uses of the affordance of "independent escape route" for a racoon that the racoon can see (p. 125). The quote below also places affordances in the environment: "To summarise, animals, plants, and even microorganisms are equipped with competences that permit them to deal appropriately with the affordances of their environment" (p. 101). This suggests more of a Turvey-style than Reedstyle view of affordances, whereby affordances are of the environment, but animals, plants or microorganisms need competences to bring them out. ${ }^{2}$

However, a different take on affordances, which stresses the role of the biological history of animals in shaping affordances, is also visible in Dennett's writing, where he speaks of inherited affordances: "The offspring inherit a manifest image with an ontology of affordances from their parents and are born ready to distinguish the things that are most important to them" (p. 123). Inheriting of affordances in a 'manifest image' suggests a stronger, even representational claim about affordances.

These two positions-affordances in the environment vs. affordances being hereditary-already conceptualise affordances in at least a dramatically different way. This is not the last of it, for Dennett also seems to be in agreement with socio-historical accounts of affordances in the likes of Chemero's, or Rietveld \& Kiverstein's, when he speaks of wanting to "expand his account to include not only affordances of plants and other nonanimal evolvers but also the artifacts of human culture" (p. 119).

It seems that we cannot have all of these varieties of affordances in the same story, without making explicit exactly to which one we are committing, as they, at face value, look contradictory. For example, it seems impossible for the same concept of an affordance to be referring

\footnotetext{
${ }^{2}$ Although the term 'affordances of their environment' can be also interpreted in the Bickhard and Richie's (1983) representational sense, this interpretation of Dennett's use of the term 'affordance' seems not likely to hold in relation to the capacities of microorganisms and raccoons.
} 
to environmental relations, manifest images, or social practices. ${ }^{3}$ Alternatively, we must clarify how it is conceptually possible to have them all, and how they interact within one philosophical account. The latter is an option if one properly names these variations of affordances (A1, A2... An), and shows how they interrelate without being contradictory. Perhaps some of them will lose the status of an 'affordance'. But in order to understand Dennett's philosophy, determining the one true affordance is not the objective; it is rather to clarify which one might be the most useful notion, i.e., the one with the greatest function, for his evolutionary account of cognition. For example, the metaphysics of affordances might be determined after considering their pragmatics: what is it that we do with affordances, and how do we act on them?

\section{What do we do with affordances?}

The conception 'affordance' gets even more complex as we move on to another context: the relationship between affordances and information. This is a rather new and exciting approach to affordances that is found in Dennett's work, but again the worry is that it raises whole bunch of problems about the way we relate to affordances.

In order to discuss semantic information and the idea that information is useful (information is used by agents "to do all manner of new things, including developing new ways of further informing themselves" (p. 119)), Dennett relies back on Gibson's approach to affordances: the view that "'the information is in the light" and it is by "picking up" the information that animals perceive the world" (p. 119). Dennett complains about how "Gibson was notoriously silent on how organisms pick up the information needed to notice, identify, and track their affordances" (p. 166), but endorses the narrative of information pick-up as a useful narrative.

This narrative of 'picking up' is then turned from information to affordances, when Dennett suggests that jazz musicians "pick up the affordances made available" (p. 133) when playing music, unlike some of their audiences. He writes:

Charlie ("Bird") Parker couldn't copyright his solos, but many saxophone players and other jazz musicians who heard them were heavily influenced by him, which is to say: valuable semantic information flowed from his performances to theirs (and not to the tin audiences who couldn't pick up the affordances made available) (p. 133)

The worry this quote raises is that there seem to have occurred an equivocation between affordances and information, suggested by the narrative of 'picking up'. Are affordances equivalent to (ecological) information? ${ }^{4}$ Are they 'picked up' like information? Or do we pick up information to track affordances? The request is here for Dennett to specify the conceptual relationship between information and affordances, and between ecological information and

\footnotetext{
${ }^{3}$ Social and cultural affordances, for example, can rule out or further constrain what one can physically do in the environment.

${ }^{4}$ This should not be the case, though Gibson himself was not clear on this distinction, as the quote below shows: "'[a]n affordance, as I said, points two ways, to the environment and to the observer. So does the information to specify an affordance' (Gibson 1979/2015: 132, emphasis added)" (see Heras-Escribano, 2019, p. 32).
} 
semantic information, as the topic of semantic information plays a crucial role in his story of evolution of intelligent design (see Chapter 6).

Also, if affordances (without being equivocated with information) are 'picked up', as the narrative suggests, does this also leave room to speak of affordances being 'created'? Dennett embraced the latter description as well, writing that "repetition is a key ingredient in creating new affordances" (p. 208), or explaining how we invent and construct affordances:

A hardware store is a museum of affordances, with hundreds of different fasteners, openers, (...) and so forth, all recognizable and usable in appropriate circumstances, including novel circumstances in which we invent and construct new affordances ad lib, using predesigned, pre-manufactured parts (p. 135).

The descriptions of picking up affordances vs. creating/inventing new affordances do not go hand in hand. The solution is not as simple as to reserve the narrative of 'picking up' to information, leaving open other forms of engagement to be compatible with affordances. The problem is with the notion of affordance one adheres to: a commitment to affordances being 'static' possibilities for engagement that allows for their 'pick up' (e.g., a cup affords drinking from, due to its respective shape and size relative to the hand grip), vs. affordances being continuously co-created and re-shaped in the ongoing interaction with the world (e.g., a cup affords drinking from, because of the ongoing practices of tea-drinking that allow us to see these possibilities for action, and due to normative constraints, whereby your cup does not afford me to drink from as my own cup does). ${ }^{5}$ In short, the way of thinking about affordances will shape our conceptions of how they are involved in our lives.

\section{Who acts on affordances, us or our brains?}

Another issue, related to the one above, can be pointed out in terms of the narrative that includes affordances in the description of the activities of the brain. Dennett writes that "Brains are control centers for dealing swiftly and appropriately with the opportunities and risks- the affordances - of a mobile life" (p. 150). We also learn about the "brain's predesigned set of affordance detectors" (p. 193). In Chapter 8 "Brains made of Brains", we read about programmers of the elevator control system anticipating difficulties in the process, "going through the work cycles of the elevator in their imaginations, looking out for affordances positive and negative" (p. 152), suggesting top down problem-solving (and strictly human engagement with affordances), only to contrast it with bottom-up designs provided by evolution. Then, we encounter a question "how do brains pick up affordances?" (p. 165). In another chapter, we also read that "Brains are well designed for picking up affordances of all kinds and refining the skills for responding to them appropriately" (p. 274).

\footnotetext{
${ }^{5}$ One can also imagine that drinking from cups may be looked down upon or banned one day (e.g., because they are plastic), and cups will therefore lose their 'drinking' affordances. While this particular scenario is not very likely, such considerations are at place from an ethical perspective. For example, certain clothes afford wearing in the accepted context of a film costume (dressing up as a person of another race or culture for a movie set), but it may no longer afford it in other social settings, like a Halloween party.
} 
In light of the abovementioned discussion, it should be clear why such descriptions yield confusion. The suggestion that it is brains, not people, that (also) pick up affordances, introduces yet another level of complexity to the understanding of the role of affordances in the overall project. Even if, for argument's sake, one thinks of people as brains, and therefore equated the pickup of affordances by us and by our brains to the same process, this would not help in understanding the pick-up of affordances referring to socio-historical developments, not just environmental properties.

Moreover, if the brain (separate from the person) is somehow involved directly with affordances, is it picking them up or creating them? Dennett writes that the brain "works as an expectation-generating organ, creating new affordances on the fly," and that "Bayesian predictive coding is a method for generating affordances galore" (p. 168). Assuming that the brain is not equivalent to the person, does the brain create new affordances by predicting possibilities thanks to predictive coding mechanism? How can a brain create affordances, understood as relations between the animal and its environment? What kind of brain activity's output is that? And does it still make sense for us to speak this way?

Dennett refers to the idea that brains are prediction machines, and tries to tie it with the concept of affordances. Since seeing of possibilities for action in situations could be understood as involving a prediction-mechanism (under the description that affordances refer to possibilities that are factually 'not there'), one could try to provide some connection between the Bayesian characterisation of the brain and affordances. However, this picture steps far away from some of the ecological notions of affordances (where affordances already populate the 'Umwelt', as Dennett notices, or are present in the socio-historical 'forms of life'). In short, the move tying brains to affordances cannot be made without further clarification and argument.

\section{Conclusion: Out of the rabbit hole?}

We see how not having a clear ontology of affordances stands in a way to fully understand what role affordances play in a holistic, evolutionary story of cognition that Dennett tries to provide. It does not help that from Chapter 9 onwards, we see reference to words (p. 198), memes (p. 287) and cultural artefacts (p. 233) as affordances as well, though that seems perhaps to be on a better track, because here Dennett describes affordances in the context of sociocultural engagements-even though the brain's connection to affordances is sometimes reintroduced in a very puzzling way ("Words are affordances that our brains are designed (by evolutionary processes) to pick up" (p. 204); "there may be many different ways of embodying (embraining?) the mastery of an affordance" (p. 272)).

How can we then control the affordance talk? How can we make sure to do right by the original idea, and at the same time implement one of its meanings in the most fruitful way in our projects?

Bringing together modern cognitive science with ecological psychology is in my view an admirable feat, and a proposal that is indeed more and more discussed. For example, Golonka \& Wilson (2012) have suggested ways that ecological psychology can make hypotheses about the world and act as a 'guide to discovery' for cognitive scientists; Bruineberg et al. (2018) 
have attempted to integrate the predictive coding analogy in an affordance-based model of cognition. There may even eventually be a place for the discussion of brain activities in the cognitive model that includes affordances. Yet, such discussions have to be handled with care, and the levels of description (human agent vs. brain) have to be integrated thoughtfully, otherwise reference to affordances will not play a useful role in the explanation of cognition. In modern philosophy of cognitive science, affordances already have a 'bad rap', and by many they are not seen as explanatorily useful. My worry is that this book does not help affordances in gaining a better scientific stand. The status of affordances needs to be clear, if affordances are to play a useful role in illuminating the nature of cognition, let alone playing an actual scientifically-respectable explanatory, predictive or descriptive role.

Why speak of the connection between the brain and affordances, if not for the conviction that affordances can play some useful explanatory work not captured so far? Here I would like to consider the questions 'how come' and 'what for' that Dennett proposes in the book, and contrast them to the question 'how'. In Chapter 3, we learn about reasons and causes. Dennett argues that "there is no essential line dividing them" (p. 49)-them referring to 'how come' and 'what for' questions. This seems right, considering that both questions are types of 'why' questions. Why ('what for') is the organism behaving this way? Why ('how come') is the organism behaving this way? What for asks for reasons, and suggests there is a purpose to why something is occurring (here, for example, a teleosemantic explanation might be fitting). How come is supposed to track distal causes: we're looking at why something had occurred in the first place (here, a dynamical systems approach can be illuminative, which gives holistic explanations). Affordances may fit the 'how come' type of why explanations: the way the environment is shaped and our (socio-cultural) manners of interacting in it is the reason how come we respond to it the way we do.

But others in the field, such as Gładziejewski (2015), have drawn the line between a different set of questions: Why and How. 'How come' and 'what for' would be essentially captured by the 'Why' category; the 'How' category tracks something else: proximal causes. How does the system work now? The occurrence is often modelled on a mechanism, and a story of how component parts causally connect is proposed. Such story is said to be advantageous for cognitive scientists, as the occurrence can be modelled and therefore recreated. Giving answers to How questions is currently the accepted practice of giving explanations in cognitive science, as opposed to giving constitutive descriptions.

When explanation is thus construed, affordances may not have a place in the explanatory story. ${ }^{6}$ Yet, there are interesting proposals emerging in the cognitive science literature that question the assumption about proximal causes being the only scientifically respectable explanatory notions. This includes the debate on the meaningfulness of the causal-constitutive divide for (social-)cognitive phenomena (Leuridan, 2012), the reach of mechanistic explanations to wide phenomena accounted for by E-Cognition (Miłkowski et al., 2018), or the placement of temporality in the structure of explanatory models (Krickel, 2018; Abramova \& Slors,

\footnotetext{
${ }^{6}$ Ecological psychologists and embodied mind theorists often accept the same distinction, when they claim that they are not interested in providing explanations or answering the 'How' questions, but are only interested in the historical 'Why' questions.
} 
2018; Gallagher, 2018). The rationality of drawing a sharp separation between distal 'how come' vs. proximal 'how' explanations when explaining complex cognitive phenomena is therefore currently under heated discussion.

This means that the place for affordance talk in connection to the workings of the brain may be in the end granted, in a wide-explanatory proposal of cognitive workings that surpasses the current divides. There may be a place for affordances not just in ecological cognitive science, but in mainstream cognitive science as well, where they get to be part of new 'how' explanations. ${ }^{7}$

But we do not reach that goal faster by introducing claims such as 'the brains pick up affordances'; we are simply not there yet to make sense of such talk. What is needed is a clear ontology of affordances, and a consistent commitment to one of its notions (even if not the original one) to serve the purpose of the project the best.

To summarise, I have shown that in From Bacteria to Bach and Back, the notion of affordance is used in multiple ways, but as there exist incompatible notions of 'affordances' in the literature (as properties vs. as relations, environmental vs. biological/relational, individual vs. sociohistorical), which notion of affordance serves Dennett best is not clear. Also, since Dennett refers to affordances in at times contradictory ways (picking up vs. creating, done by people vs. done by brains), it may be worrisome if the 'positive shout out' to this notion is in fact so positive, or if, to a sceptical reader, it only re-affirms the problems affordance-talk faces. Yet, Dennett's work captures the very rich variety or roles that the notion of affordance can be associated with, opening the door to further discussion of the explanatory posits of cognitive science. The suggestion of this commentary is that a proper analysis of this notion is indispensable to reinforce the place of affordances as useful constructs, and strengthen Dennett's evolutionary argument. This task will not only help in the overall clarification of Dennett's scientific project; it can help to shape the future methods of cognitive science as well.

\section{Acknowledgements}

This work was made possible thanks to the Research Foundation Flanders (FWO) grant 'Enactive Approach to Pretending' [12J0419N] and the Polish Academy of Sciences project 'Cognitive Science: In Search of Unity'. I would like to thank Erik Myin, Marcin Miłkowski, Shaun Gallagher and Daan Dronkers for comments on the earlier version of this paper.

\section{References}

Abramova, E., \& Slors, M. (2019). Mechanistic explanation for enactive sociality. Phenomenology and the Cognitive Sciences, 18(2), 401-424.

Bickhard, M. H., \& Richie, D. M. (1983). On the nature of representation. New York: Praeger.

\footnotetext{
${ }^{7}$ Perhaps the debates open up a possibility of thinking of affordances in some wide-causal way: seen as related to the constraints of the (social) environment, affordances can be understood as necessary conditions for events, and maybe even find a place within wide mechanistic explanations of cognition.
} 
Bruineberg, J., Kiverstein, J., \& Rietveld, E. (2018). The anticipating brain is not a scientist: the free-energy principle from an ecological-enactive perspective. Synthese, 195(6), 2417-2444.

Chemero, A. (2003). An Outline of a Theory of Affordances. Ecological Psychology 15(2): 181195.

Chemero, A. (2009). Radical Embodied Cognitive Science. Cambridge, MA: MIT Press.

Dennett, D. C. (2017). What Scientific Term or Concept Ought to be More Widely Known?: Affordances. Edge. Retrieved from https://www.edge.org/response-detail/27002

Dennett, D. C. (2017). From bacteria to Bach and back: The evolution of minds. New York: WW Norton \& Company.

Gallagher, S. (2018). New mechanisms and the enactivist concept of constitution. In M. P. Guta (ed.) The Metaphysics of Consciousness (pp. 207-220). London: Routlege.

Gibson, J. J. (1979). The Ecological Approach to Visual Perception. Boston, MA: Houghton Mifflin.

Gibson, J. J. (1982). Notes on affordances. In E. Reed and R. Jones (Eds.), Reasons for realism: The selected essays of James J. Gibson (pp. 401-418). New Jersey: Lawrence Erlbaum Associates.

Gładziejewski, P. (2015). Explaining cognitive phenomena with internal representations: A mechanistic perspective. Studies in Logic, Grammar and Rhetoric 40(1): 63-90.

Golonka, S., \& Wilson, A. D. (2012). Gibson's ecological approach. Avant: Trends in Interdisciplinary Studies 3(2), 40-53.

Heras-Escribano, M. (2019). The Philosophy of Affordances. Cham, Switzerland: Palgrave Macmillan.

Krickel, B. (2018). Saving the mutual manipulability account of constitutive relevance. Studies in History and Philosophy of Science Part A 68: 58-67.

Leuridan, B. (2012). What are mechanisms in social science? Metascience 21(2): 395-398.

Miłkowski, M., Clowes, R. W., Rucińska, Z., Przegalińska, A., Zawidzki, T., Gies, A., Krueger, J., McGann, M., Afeltowicz, Ł., Wachowski, W. M., Stjernberg, F., Loughlin, V., Hohol, M. Stjernberg, F. (2018). From wide cognition to mechanisms: a silent revolution. Frontiers in psychology 9 (1-17).

Noë, A. (2004). Action in Perception. Cambridge, MA: MIT Press.

Reed, E. S. (1996). Encountering the World: Toward an ecological psychology. New York: Oxford

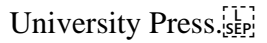

Rietveld, E. \& Kiverstein, J. (2014). A Rich Landscape of Affordances. Ecological Psychology 26(4), 325-352.

Rucińska, Z. (2017). The Role of Affordances in Pretend Play. In C. Durt, T. Fuchs, \& C. Tewes (Eds.), Embodiment, Enaction, and Culture: Investigating the Constitution of the Shared World (pp. 257-277). Cambridge, MA: MIT Press. 
Turvey, M. T. (1992). Affordances and Prospective Control: An Outline of the Ontology. Ecological Psychology 4(3): 173-187.

Varela, F. J. (1988). Structural Coupling and the Origin of Meaning in a Simple Cellular Automaton. In E. E. Sercarz et al. (Eds.), The Semiotics of Cellular Communication in the Immune System (pp. 151-161). Heidelberg: Springer.

Varela, F. J., Thompson, E., and Rosch, E. (1991). The Embodied Mind: Cognitive Science and Human Experience. Cambridge, MA: MIT Press.

Withagen, R., H. J. de Poel, D. Arauja, and G. Pepping. (2012). Affordances can invite behaviour: Reconsidering the relationship between affordances and agency. New Ideas in Psychology 30: 250-258.

The editorial and publishing process of this publication has been financed by the Ministry of Science and Higher Education from the funds for the dissemination of research (DUN) within the framework of publishing activity, contract no. 711/P-DUN/2019, period of implementation: the years 2019-2020. 